Boise State University

ScholarWorks

9-1-2009

\title{
Faculty Field Guide for Promoting Student Civility in the Classroom
}

Cynthia Clark

Boise State University 


\title{
Faculty Field Guide for Promoting Student Civility in the Classroom
}

\author{
Cynthia M. Clark PhD, RN \\ Authors' Affiliation: Professor Department of Nursing, Boise State University, Boise, Idaho \\ Corresponding Author: Dr. Clark, Department of Nursing, Boise State University, 1910 University Drive, Boise, ID \\ 83725-1840 (cclark@ boisestate.edu).
}

Citation: Clark, C. M. (2009). Faculty field guide for promoting student civility, Nurse Educator, 34(5), 194-197.

\begin{abstract}
Student incivility is defined as rude and disruptive behavior that, when left unaddressed, may spiral into aggressive or violent behavior. Nursing faculty are challenged by uncivil student behavior and many are underprepared to deal with its effects. Some faculty members consider leaving academe due to the serious toll incivility often takes on their personal and professional lives. The impact of student incivility on faculty is especially troubling during a national nursing shortage. The author provides nursing faculty with several ready-to-use strategies for preventing and effectively dealing with student incivility in nursing education.
\end{abstract}

In recent years, violent acts on American college campuses have seized headlines and captured the attention of faculty and students in higher education. Faculty must be alert to potential acts of aggression, but they must also be attentive to lesser acts of incivility that can escalate into violence or undermine the learning environment for faculty and students. Academic incivility is defined as rude, discourteous speech or behavior that violates the norms of mutual respect in the learning environment (1). Acts of incivility not only negatively impact the learning environment, but they can escalate into hostility and violence (2) or spiral into aggressive or violent behavior (3).

Research in nursing education $(4,5)$ reveals that acts of student incivility have increased over the past several years. Some nurse educators fear for their personal safety as a result of uncivil student encounters, and others experience physical and psychological symptoms, causing them to doubt their abilities as educators $(5)$. Other studies $(6,7)$ found that stress, faculty arrogance, and pressure related to balancing multiple roles contributed to nursing student incivility. Similarly, Clark $(2,8)$ found that incivility in nursing education can result in psychological and physiological distress in both groups and can negatively impact the academic environment. Unresolved student anger can manifest in destructive ways (9), and because uncivil student behavior threatens the academic environment, faculty must be equipped to effectively address these behaviors to prevent acts of violence (10). When incivility is minimized, acts of violence decrease (11). Therefore, it is imperative to prevent and manage student incivility in nursing education to enhance the safety and quality of the educational environment. 


\section{Conceptual Framework}

The Public Health Approach to Violence Prevention Model (12) is used to frame the problem of incivility in nursing education. The model is a systematic process that involves defining the problem, identifying risk and protective factors, developing and testing prevention strategies, and assuring widespread adoption. The first step in preventing violence is to understand it and to identify the factors which contribute to it. In the Clark study, $(2,8)$ students reported that being highly stressed, overworked, and over-extended with family, work, and school demands contributed to student incivility.

The second step of the prevention model identifies risks and protective factors. Clark $(2,8)$ identified some of the potential risks associated with student incivility including stress due to burnout from demanding workloads, perceived competition in a high-stakes academic environment, as well as an intense competition for grades and scholarships. A lack of clinical experience, fear of making mistakes or harming a patient, and concern about faculty evaluation of student performance also contributed to student incivility (13). Prevention strategies are needed to address these risk factors to prevent disruptive student behaviors from escalating into more dangerous situations.

The third step of the prevention model is to develop and test prevention strategies. These strategies include addressing uncivil behaviors swiftly and fairly, developing and implementing comprehensive policies for prevention and intervention, offering ongoing education, and providing open forums for candid dialog between faculty and students (8). While these conversations may be uncomfortable, engaging in respectful conflict negotiation helps prepare students for real-life situations (9).

The final step of the prevention model calls for wide spread adoption of effective strategies. This article provides nursing faculty with several evidence-based and anecdotal ready-to-use strategies to foster a safer learning environment and to promote a culture of civility in nursing education.

\section{Faculty role modeling}

Professional role-modeling is critical for student development and for socialization into the nursing profession. The faculty role includes modeling professional behavior, attire, language, and communication. Effective communication can be modeled by using respectful language, maintaining inclusive attitudes, teaching and demonstrating civil discourse, and listening to students (14). To be effective role models, faculty must be aware of their own behavior. Some faculty create an adverse learning environment by belittling or demeaning students, asserting their superiority, or making sarcastic or condescending remarks $(2,8)$. This behavior invites uncivil student behavior as an expression of protest against perceived unfair or unreasonable treatment (15). Viewing the faculty-student relationship as a collaborative partnership instead of an authortarian relationship can help foster an empowering learning environment (16). Therefore, faculty are urged to consistently examine how their teaching methods, conduct, and communication styles can inadvertently contribute to student incivility (14). By doing so, faculty can avoid unnecessary conflict with students, and realize that they bear a unique responsibility for creating a positive learning environment 8 .

\section{Planning for success}

At the beginning of each class, faculty should clearly identify the course objectives and the level of competence that students are expected to achieve (16). Planning for a successful first day can help prevent potential problems from occurring later in the semester. On the first day of class, faculty should arrive early, dress professionally, and set a welcoming tone. Once class begins, students can be invited to stand and formally introduce themselves using their full name and sharing an item of interest related to the course. Depending on the size of the class, students can also make name tents using large index cards folded length-wise. Students can write their preferred name on the index card using a marking pen and bring their name tents to each class period so that faculty and classmates can refer to each student by name. If feasible, students can be arranged in a manner (such as semi-circles) that allows for the name tents to be visible to all class participants. This technique builds respect, collegiality, and an esprit de corps among faculty and students.

Faculty in higher education are charged with encouraging debate and engaging students in intellectual inquiry. These activities require bringing civility to discourse and respect to our conversations and encounters. Fostering a classroom environment conducive to student learning and evocative dialog is critical. Therefore, co-creating 
classroom norms on the first day of class is essential in fostering a civil environment. This process instills in students a sense of ownership and commitment to a respectful academic environment. When the faculty facilitates a process where students collectively establish norms for behavior, they are more likely to approve of and conform to them (17).

The course syllabus is an excellent tool to assist faculty with facilitating classroom discussion and establishing behavioral norms. On the first day of classes, faculty are encouraged to devote as much time as necessary to review the syllabus which includes their teaching philosophy, the course goals and expectations, and the role of civil discourse. A careful review of the syllabus can be helpful in clarifying assignments, course expectations, and expected behaviors. An ambiguous or poorly constructed syllabus may contribute to student resentment and anger (14). Conversely, a well developed syllabus can be a catalyst for co-creating norms. With faculty prompting, students commonly create norms regarding respectful communication, conflict negotiation, and use of technology during class. These norms form the foundation for expected behavior in the academic arena.

Several institutional documents and position statements can be referred to in the syllabus and utilized by faculty in the co-creation of norms. Almost every college and university has a Student Code of Conduct and many others have 'Civility Statements' emphasizing a commitment to respectful discourse and openness to opposing points of view. Civility Statements stress mutual regard, a willingness to listen, and a pledge to abide by norms of decorum and institutional values. Common institutional values often include academic excellence, caring, citizenship, fairness, respect, and responsibility. The website links for these documents can be included in the course syllabus and discussed during syllabus review. Other syllabus 'talking points' include the institution's policies for conflict negotiation, student grievance, and academic dishonesty. Many students are unaware of specific policies which afford due process and outline procedures for resolving conflict. Many others are ill-informed about issues related to cheating and plagiarism. Having an open discussion about these issues and providing the policy links in the course syllabus are useful to students. Other catalysts for dialogue include Professional Nursing Standards, Codes of Ethics, and professional behaviors and expectations. Specific behavioral objectives can be included in course syllabus along with more course-specific objectives. Students must be held accountable for behavioral outcomes in the same way they are held accountable for course-specific outcomes that must be met to pass the course. Behavioral outcomes are excellent 'talking points' and provide a platform for discussing student conduct.

Faculty must communicate clearly with students about their availability and response time. In this age of ubiquitous and high-speed technology, it is impossible and unreasonable for faculty to respond immediately to student e-mails, correspondences, and on-line postings. Therefore, faculty need to be very clear with students regarding their availability and response times since timely feedback and prompt grading are important in developing positive student-faculty connectiveness (18).

\section{Instituting cooperative and active learning strategies}

Faculty can foster positive student-faculty relationships through learning experiences that promote collaborative exchanges between students and faculty (16). Cooperative learning strategies promote student achievement; enhance communication and social skills, and increase student learning and productivity (19). Problem-Based Learning (PBL) is an example of a cooperative learning strategy whereby teachers pose a real problem for students and then have students work together to find a successful resolution to the problem (16). This strategy is particularly successful in clinical nursing education (20). Active learning strategies must be carefully constructed to ensure that students are contributing in equitable and meaningful ways. To do this, groups can be assigned a project where all members need to sign off and are given a group or an individual grade, assigning each student a part of the total task, or randomly assigning students to speak for the group (19). Involving students in active learning strategies minimizes disruption by promoting cooperation and collaboration, increases student engagement, and reduces classroom incivility (21).

\section{Assessing the learning environment}

Faculty and student classroom observations and evaluations can help improve college teaching. It may seem daunting to have others observe one's teaching methods and provide feedback for improvement, but these can be very helpful activities. Classroom Assessment Techniques (CAT) (22) help faculty obtain useful feedback about how well students are learning. The "One Minute Paper" is an example of a simple CAT that can be used to measure student learning as well as student perceptions of the academic environment. Luparell (23) suggests handing note cards out to students and asking them to identify troublesome behaviors and to make suggestions for addressing the 
problem. Student feedback may detect patterns (both positive and negative) or issues that can be addressed to prevent or diffuse academic incivility. Showing a willingness to evaluate one's own work while seriously considering student observations can contribute to a respectful learning environment (14). Student assessments not only improve teaching and learning outcomes, they also provide students with a sense of involvement and engagement in the learning process.

\section{Partnering with Student Services}

Today, higher education is faced with many difficult challenges including diverse student populations, diminishing resources, accessibility issues, and eroding public trust. Thus, Academic Services and Student Services (SS) need to work together to meet these challenges. Within the culture of academe, there are varying mental models that reflect the basic assumptions and beliefs that guide the thoughts and behaviors of various individuals (24). For example, faculty tends to value teaching, curriculum, and scholarship-while SS professionals tend to value co-curricular activities and student involvement in campus initiatives. In addition, students bring their own sets of competing assumptions to campus. Therefore, it is imperative for all groups to work together to develop effective partnerships committed to promoting student civility.

Academic and SS professionals need to communicate frequently and collaborate to develop fair and non-punitive codes of conduct. Student Services professionals should be regularly invited to nursing department meetings to forge partnerships and to work as a unified team to develop strategies for prevention and intervention of disruptive student behaviors. Academic and SS professionals can work together to develop a confidential mechanism for detailing student misconduct so that appropriate follow-up can occur and resources can be provided to reinforce appropriate student behavior.

Faculty have a professional and ethical responsibility to provide a safe learning environment. Student conduct should not present a danger (or reasonable assumption of danger) to the student or another person. To ensure compliance with these standards, many colleges and universities have developed policies that govern student behavior. In most policies, faculty are required to notify their supervisor to enlist their support in resolving the problem. These policies must be implemented and faculty must act swiftly and fairly when acts of incivility occur. Silence or inaction may be viewed as condoning the behavior. Faculty interventions include referring to classroom norms or standing near the student whose behavior is disruptive. Standing near the student in a non-threatening manner while simultaneously providing an arm's length distance may decrease the disruptive behavior.

Another faculty intervention includes calling a short break. During the break, faculty can speak privately to the student and ask for an adjustment in behavior. If this intervention is unsuccessful, the faculty member can ask the student to leave the class. The incident needs to be reported to one's supervisor, carefully documented, and a followup meeting should be scheduled with the student. The purpose of the meeting is to seek resolution and to have the student refrain from further disruptive behavior.

Before meeting with the student, the faculty member should inform his or her colleagues about the meeting on a need-to-know basis so they can be available to assist if necessary. If a faculty member is uneasy about the meeting, it is helpful to have an objective third party present. Arrange the meeting room in a manner that does not block faculty access to an exit or consider meeting with the student with the door open. During the meeting, the faculty member should avoid defensiveness, assume an open demeanor, speak in behavioral terms, and use a nonthreatening approach. Faculty can refer to established behavioral norms, focus on behavioral objectives, and should listen carefully to the student's perspective. Faculty should secure agreement for improved behavior; refer the student to assistive campus resources, and implement relevant policies and procedures. If at any time, a faculty member feels uncomfortable or ill-prepared to meet with a disruptive student, the supervisor should be notified. Referrals to the SS office should be made if the problematic behavior exceeds one's skill level, the behavior is getting progressively worse, personality differences prevent objectivity, or if the faculty member is unsure about how to proceed. For an example of a comprehensive policy for disruptive student behaviors see Clark, Farnsworth, and Springer (25). 


\section{Providing open forums}

To successfully deal with incivility it must be named and publicly discussed. Incivility and its damaging consequences must be revealed-otherwise we are powerless to effect meaningful change. Conducting open forums where ideas and concerns can be freely exchanged not only models respectful discourse and disagreement, but also demonstrates how discussion of varying opinions, diverse viewpoints, and differing beliefs can help build a respectful environment. An open exchange of ideas helps foster a civil campus community.

\section{Creating a Culture of Civility}

Faculty play an important role in creating a culture of civility in nursing education. Long-term, sustained change requires faculty involvement, capable leadership, and a supportive campus infrastructure. Academic civility starts with creating a zestful workplace where faculty and administrative colleagues engage in civil exchanges and where co-workers show respect for one another (26). To foster the conditions that make for zestful academic workplaces, faculty must dialogue about the culture they want to create and secure formal agreement about how they will treat one another (27).

Faculty can partner with academic leaders to revise vision and mission statements and codes of conduct that address and reinforce a civil campus community. Faculty must be willing to address incivility, and to participate in developing and implementing comprehensive policies for student conduct. Faculty can take part in ongoing education, training seminars, and open forums to discuss and seek resolution regarding these issues. Faculty can volunteer to lead or be a member of a campus 'Civility Team' whose function is to define expected behaviors, develop policies and procedures, create a non-punitive reporting system, and to provide faculty and student support. Institutionalizing change requires broad-based, sustained support from leadership, key stakeholders, and faculty. Faculty can attend 'civility' workshops; develop an informational campus 'civility' website, and advocate for a 'civility liaison' to consult with faculty. Incentives can be given to faculty for participating in civility-promoting activities and faculty can be rewarded for their efforts to cultivate a culture of civility in nursing education.

\section{Summary}

Incivility in nursing education requires attention from all members of the academy. Faculty are in a unique position to effect meaningful change and to play a key role in creating a culture of civility. Positive faculty-student relationships promote empowering learning environments. Therefore, faculty may foster these positive relationships through professional role modeling, careful planning, and implementation of cooperative learning strategies and ongoing assessment. Partnering with other campus professionals and providing open forums are effective strategies for creating a culture of civility in nursing education.

Acknowledgements: The author gratefully acknowledges Kathleen $\mathrm{T}$. Heinrich $\mathrm{PhD}, \mathrm{RN}$ for her review of this manuscript and for her courageous efforts to foster zestful workplaces in nursing education.

\section{References}

Feldman LJ. Classroom civility is another of our instructor responsibilities. College Teaching. 2001;49(4):137-140.

Clark CM. Faculty and student assessment and experience with incivility in Nursing Education. $J$ Nurs Educ. 2008; 47(10), 458-465.

Andersson LM, Pearson CM. Tit for tat? The spiraling effect of incivility in the workplace. Academy of Management Review. 1999;24(3):452-471.

Lashley FR, deMeneses, M. Student civility in nursing programs: A national study J Prof Nurs. 2001;17(2):81-86.

Luparell, S. Faculty encounters with uncivil nursing students: An overview, J Prof Nurs. 2004;20(1):59-67. 
This is an author-produced, peer-reviewed version of this article. The final, definitive version of this document can be found online at Nurse Educator 34 (5), published by Lippincott, Williams \& Wilkins. Copyright restrictions may apply. doi: 10.1097/NNE.0b013e3181b2b589

Clark CM, Springer P. Incivility in nursing education: Descriptive study on definitions and prevalence, $J$ Nurs Educ. 2007;46(1):7-14.

Clark CM, Springer P. Thoughts on incivility: Student and faculty perceptions of uncivil behavior in nursing education. Nurs Educ Perspect. 2007:28(2):93-97.

Clark C. The dance of incivility in nursing education as described by nursing faculty and students. Adv Nurs Science. 2008;31(4): E37-E54.

Shirey MR. Stress and burnout in nursing faculty, Nurs Educ. 2006;31(3):95-97

Ehrman G. Managing the aggressive nursing student. Nurs Educ. 2005;30(3):98-100.

Forni PM. The civility solution: What to do when people are rude. New York: St. Martin's Press: 2008.

National Center for Injury Prevention and Control, Division of Violence Prevention. Available at http://www.cdc.gov/ncipc/dvp/dvp.htm Accessed February 12, 2009

Sharif F, Masoumi S. A qualitative study of nursing student experiences of clinical practice. BMC Nursing. 2005;4(6):1-7. Available at: http://www.pubmedcentral.nih.gov/picrender.fcgi?artid=1298307\&blobtype=pdf Accessed February 12, 2009.

Morrissette PJ. Reducing incivility in the university/college classroom. [Electronic version]. International Electronic Journal for Leadership in Learning, 2001:5(4):1-12.

Boice B. Classroom incivilities. Research in Higher Education, 1996;37:453-486.

Billings DM, Halstead JA. Teaching in nursing: A guide for faculty, (3 ${ }^{\text {rd }}$ ed.). St. Louis: Saunders-Elsevier: 2009.

Nilson LB \& Jackson NS. Combating classroom misconduct (incivility) with Bill of Rights. Paper presented at the $4^{\text {th }}$ Conference of the International Consortium for Educational Development (2004, June 21). Available at: http://www.uottawa.ca/services/tlss/iced2004/pages/nan.htm Accessed February 12, 2009.

Rieck S. Crouch L. Connectiveness and civility in online learning. Nurs Educ in Prac, 2007;7(6):425 - 432.

Nilson LB. Teaching at its best: A research-based resource for college instructors. (2nd ed.). Bolton, MA: Anker Publishing: 2003.

Rideout E. Transforming nursing education through problem-based learning. Sudbury, MA: Jones and Bartlett: 2001.

Gonzales V. Lopez E. The age of incivility: Countering disruptive behavior in the classroom, AAHE Bulletin. $2001 ; 55(8): 3-6$.

Angelo TA, Cross KP. Classroom assessment techniques: A handbook for college teachers (2nd ed.). San Francisco, CA: Jossey-Bass; 1993.

Luparell S. The effects of student incivility on nursing faculty. Jour of Nurs Educ. 2007; 46(1):15-19.

Komives SR. Woodard DB. Student services: Handbook for the Profession, (4 ${ }^{\text {th }}$ ed.). San Francisco: Jossey-Bass; 2003.

Clark CM, Farnsworth J, Springer PJ. Policy development for disruptive student behaviors, Nurs Educ. 2008;33,(6):259-262. 
This is an author-produced, peer-reviewed version of this article. The final, definitive version of this document can be found online at Nurse Educator 34 (5), published by Lippincott, Williams \& Wilkins. Copyright restrictions may apply. doi: 10.1097/NNE.0b013e3181b2b589

Heinrich KT. Joy-stealing: How some nurse educators resist these faculty games. Reflections on Nursing

Leadership. 2006, third quarter. Available at: http://www.nursingsociety.org Accessed November 25, 2008.

Heinrich, KT. An optimist's guide to cultivating civility among academic nurses, Jour Prof Nurs, (in review). 